\title{
Los modelos de la tipología del teatro a finales de la llustración en España
}

\author{
José Enrique Garcia Melero
}

\begin{abstract}
«Tutte le belle arti, e le scienze più utili hanno da concorrere alla formazione de'teatri». (Milizia, «Principi de Architettura civile». Finale, 1781, vol. II, pág. 426).
\end{abstract}

El reciente incendio del Liceo de Barcelona, comentado ampliamente por todos los medios nacionales e internacionales de comunicación, proporciona una idea bastante elocuente de la importancia que el teatro, tipología peculiar arquitectónica con sus diversos modelos y distintas modalidades, sigue teniendo en la actualidad. Ello sucede así, porque el edificio para los espectáculos fue, y aún en nuestros días continúa siendo, uno de los grandes símbolos identificadores de la ciudad junto, por ejemplo, con la catedral, el palacio o la plaza, dotando a la urbe de especificidad formal y cultural, que sirve para medir su mismo pulso vitalista.

El edificio del teatro alcanzó cuantitativa y, quizás, hasta cualitativamente su momento más importante en nuestro país durante el siglo XIX, después de dedicarse a la práctica de esta tipología a un nivel europeo arquitectos de tanto interés y tar novedosos por su aportación a lo largo de la Historia y desde el Renacimiento como, por ejemplo, los italianos Palladio, Scamozzi, Aleotti, Fontana, Juvarra y los Galli Bibiena, o los franceses Boullée y Ledoux, quienes introdujeron innovaciones en las plantas. Pero su período de máximo esplendor se desarrolló, es muy posible, durante el romanticismo histórico, al obtener la burguesía el pleno permiso, dado por la Revolución Francesa que confirmó un derecho rompiéndose, así, una vez más con la sociedad estamental- de acceder a la cultura de la aristocracia, en algo más intelectual por desconocida y, quizás, abstracta.

Entonces se construyeron por toda Europa magníficos y hasta suntuosos teatros públicos de una gran capacidad, que sustituyeron a los 
cortesanos más pequeños en muchos paises. En estos últimos, como en los primeros de iniciativa privada de Italia, se habían desarrollado principalmente los experimentos arquitectónicos tanto en la planta como en los palcos y en el empleo de los distintos materiales para adecuarlos a las necesidades de la óptica y de la acústica, las dos coordenadas científicas que condicionan desde el punto de vista constructivo este tipo de edificio.

La ópera y el concierto constituian hasta entonces una actividad cultural bastante minoritaria en España. Estos géneros musicales parecían más abstractos e intelectuales para el pueblo que el teatro dramático, en algo más concreto, debido, sobre todo, a que la mayoría de la población no había recibido una enseñanza musical adecuada. Pero en muchos de los paises europeos durante las décadas iniciales del siglo XIX la música culta pasó de ser una de las principales manifestaciones del patrimonio cultural casi exclusivo de un antiguo estamento minoritario, históricamente privilegiado en torno a la Corte, a identificarse con una nueva clase social. La burguesía desde entonces poseedora del dinero dispondrá con él del poder necesario para participar tanto en el disfrute de esa misma manifestación estética como en su gestación y en proporcionar, asimismo, los medios arquitectónicos necesarios para su desarrollo más adecuado. Cambios como éste marcarían la Historia de esa centuria en todos sus diversos aspectos y entre ellos, obviamente, en el de la arquitectura.

El inicio de tal mutación también se puede percibir, aunque algo tímidamente, en la España de las décadas finales del siglo xvIII; pero las principales realizaciones por su número e interés tuvieron lugar sobre todo entre 1832 y 1875 durante el reinado de Isabel II. La Academia de la llustración participó consciente, y a veces hasta inconscientemente, en ella como instituto máximo de enseñanza y del control del arte. Desde tal centro se intentó normalizar una serie de modelos arquitectónicos como alternativa por su misma condición de ejemplos a seguir, para que sirvieran en calidad de códigos del clasicismo a la hora de enseñar a sus discípulos, los futuros arquitectos, y de realizar la censura de las obras públicas desde la Comisión de Arquitectura. La labor didáctica de los profesores, menos perceptible a simple vista y de consecuencias prácticas a medio plazo de tiempo, y las publicaciones realizadas entonces propiciaron la eclosión de la arquitectura teatral en el tránsito entre ambas centurias y su apogeo durante la época isabelina.

Si algo delimita la situación tipológica de este edificio en España durante los inicios del siglo XVIII en relación con los teatros, que se estaban construyendo en el resto de Europa, es, quizás, su carácter bastante provinciano por retardatario y su aislamiento, tal y como ocurría en otras 
modalidades de construcciones. Pero la entronización de los Borbones significó el comienzo de la ruptura con la marginidad artística a todos los niveles al percibirse política y conscientemente la decadencia manifiesta al perder el ritmo europeo y dejar de ser una primera potencia. Esta nueva dinastía trajo consigo otros aires arquitectónicos más internacionales y universalistas, pero siempre a remolque de los huracanes, sobre todo, italiano y francés, de lo que se hacía en Italia y en Francia.

Lo mismo estaba sucediendo en otros paises europeos debido a la difusión y al arraigo de las ideas de la llustración y al carácter internacional de la redescubierta tendencia clasicista en boga entonces. Muchas naciones también vivían en gran medida de lo hecho en la parcela concreta de la arquitectura del teatro, sobre todo en Italia, el auténtico laboratorio de modelos, y en Francia con su labor al mismo tiempo de difusión y, asimismo, de experimentos funcionalistas, clasicistas y visionarios en las décadas finales de esa centuria. Para ello se partió en este Reino del clasicismo como referencia hasta recrear otra cosa en virtud del necesario funcionalismo de la época. Y así se llegó a la arquitectura «parlante», aquélla cuya forma es respuesta elocuente de su misma finalidad ${ }^{1}$.

No obstante, no había en la Europa de finales de la llustración, como tampoco durante las distintas épocas precedentes, una tipología única y universal del teatro, a la cual parecía aspirarse, sino una serie de modelos de proyectos construidos y algunos de ellos irrealizados, y hasta utópicos. Estos ejemplos del pasado y del presente eran utilizados según las preferencias personales del mecenas, del arquitecto dentro de su peculiar forma de hacer, quien debía obedecer de algún modo a tal mecenazgo, y aun del medio, en el cual se construia; pero siempre bajo la presión de la Historia. Tales modelos pueden agruparse por «tendencias» histórico-artísticas, pues poseen una serie de directrices, que suelen ser comunes en su planta, especialmente en la parte del edificio reservada al espectador, que en cierto modo concuerdan con los cambios realizados en otras obras. Se trata de ejemplos históricamente heredados por evolución, susceptibles de agruparse en «familias de modelos» dentro de esta tipología, usando aquí tal término tan sólo como factor diferenciador de otros edificios de distinta finalidad.

Una interesante historia de los teatros europeos se puede hallar en: PEVSNER, Nikolaus: «Historia de las tipologías arquitectónicas». Barcelona, Gustavo Gili, 1979. Título original: «A History of Building types». Nueva Jersey, Princenton, 1976. Véase págs. 73-106. 
Este tipo tiene como denominador común, necesariamente explícito por su misma función, la existencia imprescindible en la planta de dos partes distintas por su finalidad, pero interdependientes: la del escenario y la del espectador. Se realiza, por lo general, geométricamente en el plano, aunque no siempre dada la existencia de teatros totalmente circulares y rectangulares, en el encuentro de una línea curva, la destinada a auditorio, con la de un ángulo, que se corresponde con aquél. Pero, además, su esencia se halla en el imprescindible acomodo del edificio a las leyes de la acústica y de la óptica con todo su sistema perspectivo, que aquí deben coincidir. Tales leyes físicas, aplicadas a la arquitectura, vincula de alguna forma a los teatros con otros tipos de edificios, como la cárcel y el hospital, en los que es importante ver y hasta oír todo lo que ocurre en su interior por necesidades de seguridad.

Sin duda, hubo una evolución histórica de la planta del teatro, sobre todo, en el auditorio, el lugar reservado al público; pero también en la sustitución primero del anfiteatro por la platea y los palcos en paredes verticales y hasta escalonadas, y de éstos por las galerías ${ }^{2}$. No obstante, siempre hay que admitir interferencias formales de diversas tendencias artísticas especialmente a finales de la llustración por su estrecha vinculación historicista, aunque algunos arquitectos propusieran el retorno al teatro clásico recreado para acomodarlo a las nuevas necesidades de la época. Es posible señalar con cierto afán didáctico de generalizar que tal evolución siguió esta línea: semicircular (tendencia general clásica heredada), elíptica transversal y en forma de $U$ (reelaboración intelectual renacentista y manierista), de herradura (barroco académico), elíptica y oval longitudinal truncadas por el lado del escenario (barroco pleno y siglo XVIII) y en forma de campana (de influencia rococó).

A finales de esta centuria se pretendió por determinados arquitectos un retorno a la simplicidad del semicírculo y de la forma en $U$, afirmándose la planta de herradura en Italia y en España, y hasta la totalmente circular al modo del Panteón de Roma, tal y como si el teatro fuera un templo: el de las artes, de la música y de la literatura. Sin embargo, algunos tratadistas, como Patte inspirado en Chaumont, siguieron defendiendo el auditorio elíptico, e incluso oval, longitudinal. Lo consideraban el más apto por razones acústicas, al conjeturar que la voz humana se

Una sintesis muy atractiva sobre la historia del edificio del teatro en: FORSYTH, Michael: "Buildings for Music». Cambridge, Press Syndicate of the University of Cambridge, 1985. Traducción italiana: "Edifici per la musica". L'architetto, il musicista, il pubblico dal Seicento a oggi. (Bologna), Zanichelli, 1988. Reediciones en 1989, 1990 y 1991. 


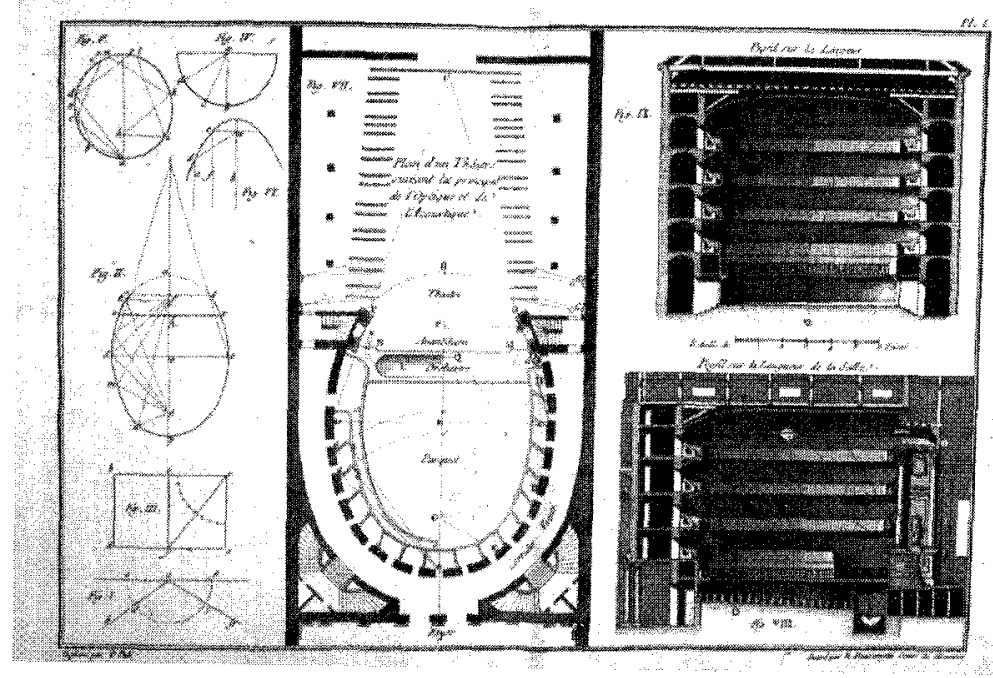

Lám. l: Proyecto de teatro con planta de auditorio en forma elíptica longitudinal de Pierre Patte incluida en su libro titulado "Essai sur l'Architecture théâtrale» (París, 1782).

difunde elípticamente, como un esferoide alargado inclinado ligeramente de abajo hacia arriba, en vez de una manera circular. Además, Patte aceptaba la planta elíptica, cuya forma se acomodaba perfectamente a la del sonido, por su bifocalidad, pues situándose el escenario en uno de sus centros, la voz, que se refleja en su contorno, iría a parar al otro centro, prolongándose su duración.

En base a esta evolución histórica de la forma de la parte de la planta dedicada al espectador, en el teatro hay, además, una serie de arquitectos que son evolutivamente figuras importantes desde el Renacimiento ${ }^{3}$. Existe, por lo tanto, un proceso formal de cambio y evolución progresivos; pero, también de retorno al orden, el afán clasicista, con una serie de protagonistas en este ir y venir, crear y recrear: Palladio, Aleotti, Fontana, Juvarra y los Galli Bibiena. Estos arquitectos son en mi opinión los principales promotores de las mutaciones en la planta del auditorio del teatro, pues crearon nuevos modelos.

\footnotetext{
3 Una visión del teatro renacentista en: Ruffini, Franco: «Teatri prima del teatro». Visioni dell'edificio e della scena tra Umanesimo e Rinascimento. (Roma), Bulzoni Editore (1983).
} 
A ellos hay que sumar el binomio teórico dieciochesco, en cierta forma contrapuesto, constituido por el francés Patte con su base formal barroca justificada pragmáticamente sobre todo en función de la acústica, y por el italiano Milizia, y su propuesta utópica clasicista. Este se valió por el contrario principalmente de la óptica para difundir un proyecto ideal elaborado de forma progresiva por varios arquitectos - Eneas Arnaldi, Tomás Temanza y Vicente Ferrarese- con los ojos puestos siempre en los modelos del clasicismo. Así, se les puede considerar como los difusores de dos sistemas distintos de base histórica en el último cuarto del siglo XVIII, principalmente entre 1771 y 1782 : el novedoso, aún siempre partiendo de la precedente tradición barroca, que es justificado racional y metódicamente, y el heredado, que ahora con el ir y venir de los estilos se puso en boga, pero con su acomodo intelectualmente funcionalista a las necesidades de una nueva época y de un espacio cerrado.

Palladio reelaboró, amanerando su modelo al intelectualizarlo y adecuarlo de alguna forma a los nuevos tiempos, la propuesta universalista, siempre vieja aspiración, del teatro de la Antigüedad greco-romana. Esta había llegado a través de Vitruvio, siendo verificada de un modo racionalista por Alberti. Así, el Renacimiento aparece al mismo tiempo como una cita y también como una interferencia del clasicismo, al que recrea y catapulta históricamente hacia esta centuria de la llustración. Palladio proporcionó un neomodelo, otra referencia proyectual al clasicismo, en el que de forma excepcional ya había estado presente. Su teatro de Vicenza ligeramente elíptico transversal -en realidad semielíptico, tal y como Patte ya señaló- significa una proyección reelaborada del pasado en el presente con perspectivas de futuro dentro de ese código, que al mismo tiempo bifurca al actualizarlo, pues el clasicismo es en última instancia siempre un afán irrepetible. De aquí que este edificio teatral palladiano, que primero siguió Scamozzi y después Aleotti con su Teatro Farnese en Parma de 1618-1628, alargando los extremos de la curva del antiteatro en línea recta en forma de $U$, sirviera de puente histórico entre esa Antigüedad y la arquitectura de la llustración ${ }^{4}$.

Interesantes estudios sobre el edificio para el espectáculo y en particular sobre el teatro en Parma en: QuinTEllu, Carlo, dr.: "La città del teatro». Seminario di progettazione architettonica. (Milano, Cooperativa libraria universitaria del politécnico.) Clup (1989). En este libro: Luigi ALLEGRI: "Le tipologie dello spazio teatrale tra storia e prospettive", págs. 161-165; Augusto Romano BURELLI: «I/ conflitto tra auditorium anfitreatrale e scena profonda nel teatro tedesco dellottocento", págs. 189-195; Guido CANELLA: L'Architettura del sistema teatrale", págs. 233-249. 
No obstante, la novedad, quizá la ruptura inconsciente con esa directriz, la proporcionó Carlo Fontana (1638-1714), quien durante diez años fue ayudante de Bernini, y en algo está marcada por el paso del edificio para la ópera desde Venecia a Roma. Cambia, así, la sede del laboratorio de nuevos modelos teatrales de un estado italiano a otro. En la ciudad de los canales este arquitecto reedificó en 1654 con la idea de adecuarlo a la ópera el teatro de San Juan y San Pablo, «inventando», pero con cierta timidez formal, la planta de herradura para la parte del espectador. Tal forma parece citar el arco de herradura del mundo islámico y a través suyo quizás el arte visigótico español. Este teatro, que reemplazaría al construido por la familia Tron al incendiarse en 1629, tiene cinco órdenes o pisos de palcos, que los arquitectos venecianos construyeron en sustitución de las gradas. El modelo fue después perfeccionado por Juvarra, maestro en arquitecturas escenográficas y al mismo tiempo escenógrafo.

Pero Fontana no proporcionó tan sólo un modelo a la tipología teatral de su época, sino dos perspectivas distintas, al pensar ya en la elipse longitudinal truncada, materializada en su tercera reedificación de 1695 del teatro romano de Tordinona y, asimismo, en la variación de su primer proyecto de óvalo truncado, también por necesidad de la existencia de un escenario. Entre su irrealizado diseño inicial de forma oval y el último elíptico, Fontana tuvo que construirlo en $\mathrm{U}$, tipo admitido clásicamente desde Aleotti. Esta línea con la doble opción elíptica u oval longitudinales se siguió en el Teatro Argentino de 1732 en Roma del Marqués Teodoli, en el Regio de Torino (1738-1740) del Conde de Castellomonte y Benedetto Alfieri... Alcanzó la segunda mitad del siglo XVIII a través de los arquitectos franceses, siendo promovida por Dumont, Chaumont y Patte. Tal planta encierra por su curva un concepto arquitectónico en algo berninesco y representativo de un barroco clasicista a lo italiano y a lo francés.

Aquí hay que situar a Patte, quien, siguiendo el debate francés en paralelo con el italiano de Eneas Arnaldi (1762) y Francisco Algarotti (1762), promovido por Dumont en 1764, Cochin en 1765 y Chaumont en 1766 con sus diversas opciones ideales, se mostró ya quizás más como un retardatario formal que como un innovador en su época. Y ello es así, aún defendiendo de un modo metódico y racionalista, tan propio de la Ilustración, un modelo de planta ideada con cierta proximidad cronológica en 1695. Pero su propuesta contradecía formalmente la opción ideal semicircular en boga entonces por ser referencial del código clásico, considerado como el verdadero estilo. Su libro fue después traducido al italiano, lo que señala el concepto siempre reversible de la influencia artística y el tono santificador de todo tratado arquitectónico. Tomó como modelo 
el Teatro Regio para formular su planta ideal elíptica longitudinal truncada, que racionalizó descartianamente para justificarla en función de que, a su juicio y con cierta influencia de Nollet, el sonido humano se difunde en forma elíptica.

A finales de la llustración las bases del historicismo decimonónico teatral de diverso signo estaban totalmente establecidas en Europa a través de las publicaciones. Algunos arquitectos revisaron, divulgando los dibujos de sus plantas, los principales teatros construidos en Europa para reafirmar científicamente la calidad de su propuesta. Pero, también, diversificaron aún más las alternativas con su proyectos ideales, proporcionando distintas opciones de la curva del auditorio, recreados del pasado. Así, Eneas Arnaldi lo pensó semicircular (1762), Francisco Algarotti, semielíptico longitudinal truncado (1762); Martín Dumont, primero con auditorio y escenario inscritos en un círculo (1764) y en un álbum posterior oval longitudinal; Cochin, oval entero transversal sobre su eje mayor al modo de Palladio (1765); Chaumont, como una elipse longitudinal aguda y truncada (1766); Francisco Milizia, un auditorio semicircular fruto de la concurrencia de un círculo que se interpenetra en un cuadrado (1771); Pierre Patte, elíptico longitudinal truncado (1782); Francisco Riccatti, de herradura (1790), el inglés George Saunders, circular truncado a tres cuartos de su diámetro (1790)... El nuevo clasicismo y el concepto universalista de la llustración promovieron ideológicamente estas propuestas de modelos ideales, en los que un racionalismo metódico a ultranza se encontraba en ocasiones en la utopía o parecía derivar de ella.

\section{LOS MODELOS DIBUJADOS, DESCRITOS Y PUBLICADOS EN ESPAÑA}

La recuperación en España de la tipología arquitectónica clásica del teatro se produjo durante la época de la llustración en gran parte, pues también pesaron los modelos de los edificios construidos o proyectados y no realizados, a través de la política de traducciones de los tratados del clasicismo seguida por la Real Academia de Bellas Artes de San Fernando. Esta directriz fue inicialmente diseñada en sus líneas principales por el consiliario Conde de Aranda en su dictamen sobre el estudio de la Arquitectura escrito hacia el año $1757^{5}$. Su idea era promover la publicación de un texto

\footnotetext{
5 "Dictamen del Conde de Aranda sobre el Curso de Arquitectura" (S.A.: 1757?, según Juan Pascual y Colome). A.A.S.F.: Leg.: 18-9/1.
} 
lo más completo posible para los alumnos de este instituto redactado por los profesores. Tal propuesta para lievar a cabo un nuevo plan de estudio de esta Bella Arte incluía la realización complementaria de un breve, pero importante, programa de reimpresiones y de traducciones de los textos del clasicismo, aspecto considerado básico para la formación de los discípulos en la Arquitectura. Entre ellas figuraban, parecía obvio, los libros de Vitruvio, Serlio, Alberti y Palladio ${ }^{6}$.

Esta política académica de reediciones de los tratados fundamentales se cumplió en gran parte durante el transcurso de la segunda mitad del siglo, en especial durante los quince años finales. Gracias a tal directriz fueron redifundidos en España, y casi siempre a través de la Academia o inspirada por ella, los diversos tipos de edificios de la antigüedad clásica, y entre ellos el teatro griego y romano como uno de los más peculiares. También se dieron a conocer sus interpretaciones y juicios personales de valor, y las reelaboraciones renacentistas y manieristas, y aun las mismas recreaciones coetáneas de la llustración.

Se aportó al mismo tiempo una visión histórica y erudita de la arquitectura de la Antigüedad, tan propia de la época, comparándose arqueológicamente los postulados teórico-prácticos propuestos en esos tratados con las ruinas llegadas del ayer para comprobar su grado de veracidad y exactitud. En tal sentido no faltaron las obras en las que se analizaban teatros españoles de la época romana para comparar estas realizaciones con los modelos griegos y romanos. El erudito traductor de Vitruvio y de Palladio, así como de Milizia, José Ortiz y Sanz, actuó de esa manera, al publicar ya en 1807 su «Viage arquitectónico-antiquario de España», cuya redacción había concluido tres años antes. Este proyecto, pues, tenía la intención de realizar un viaje describiendo todas las antigüedades arquitectónicas españolas, se quedó reducido al estudio del Teatro de Sagunto, ya que el ambiente bélico de la Guerra de la Independencia no le permitió proseguirlo ${ }^{7}$.

\footnotetext{
6 Acerca del Dictamen del Conde de Aranda sobre el estudio de la Arquitectura: GaRcia MELERo, J. E.: "Juan de Villanueva y los nuevos planes de estudio». En "Renovación, crisis, continuismo", págs. 13-56. La Real Academia de Bellas Artes de San Fernando en 1792. Madrid, Real Academia de Bellas Artes de San Fernando, 1992. Este tema es tratado en págs. 17-19.

Ortiz (Y SANZ), Josef: «Viage arquitectónico-antiquario de España». (Descripción del Teatro de Sagunto), por D... presbítero, deán y canónigo de la insigne colegial iglesia de la ciudad de San Felipe: académico de honor y mérito de la Real Academia de San Fernando: honorario de la de San Carlos de Valencia: académico correspondiente de la Real de la Historia; y bibliotecario honorario de S.M. Madrid, en la Imprenta Real, año de 1807. El texto está escrito en dos columnas: en la primera en latín y en la segunda en español.
} 
Los modelos del teatro antiguo romano, reproducidos en directo, eran especialmente esperados por los académicos de San Fernando. En 1794 Fernando Rodríguez realizó una serie de diseños del teatro romano de Mérida, que ofreció a este instituto, tan obsesionado entonces por los restos arqueológicos. Pero, sobre todo, se recordará aquí que Silvestre Pérez, pensionado en Roma, realizó una serie de doce dibujos del teatro Marcelo entre los años 1795 y 1796. Pero estos restos fueron entonces, no reproducidos con la fidelidad de una máquina fotográfica, sino racionalizados y recreados elocuentemente. Se buscaba, no obstante, siempre las líneas maestras de la obra para aplicarlas como cita funcional a la arquitectura de la época frente a la erudita de los literatos.

El aprendizaje del modelo del teatro, al que, como cualquier otra arquitectura de la época, se quiso despojar de toda referencia ornamental barroca tanto por razones estéticas como por motivos económicos, se formalizó didácticamente como un ejercicio teórico-práctico obligatorio más para los discípulos de la Academia entre las diferentes modalidades de edificios. Su conocimiento era obligatorio al ser considerado una tipología arquitectónica de rango superior, una obra mayor, exigible a los futuros arquitectos junto con otras como, por ejemplo, las del templo, el palacio, el ayuntamiento y la cárcel, el hospital, la biblioteca, la lonja... ${ }^{8}$. No en vano Vitruvio, tal y como Alberti en el siglo xV y otros tratadistas renacentistas y manieristas después harian, se había ocupado extensamente del teatro en su tratado. Así, la interpretación vitruviana clásica de este edificio fue conocida primero en la España dieciochesca por medio de la traducción al castellano de José de Castañeda, publicada en 1761, del compendio realizado por Perrault, y después por la versión de José Ortiz y Sanz de 1787.

En 1797 se publicó la segunda versión en castellano de los «Diez libros de Arquitectura" de Alberti, cuya edición príncipe bajo el título de «De re aedificatoria" habia salido a la luz escrita en latín en Florencia en $1485^{\circ}$. En el libro octavo del III tomo se incluía su interpretación de los edificios

\footnotetext{
\& En este sentido resulta significativo que Juan de Milla recibiera un $2^{\circ}$ premio de 2.. la prueba de pensado de los Premios generales de la Academia en el año 1772 por sus tres diseños de un «Teatro para las comedias españolas». Estos dibujos fueron publicados en las págs. 94-97 del libro titulado "Hacia una nueva idea de la Arquitectura". Premios generales de la Real Academia de Bellas Artes de San Fernando (1753-1831). Madrid. Real Academia de Bellas Artes de San Fernando. Comunidad de Madrid, 1992. Véase el prólogo de Delfín Rodríguez Ruiz sobre "Imágenes de lo imposible: Los proyectos de Arquitectura premiados por la Real Academia de Bellas Artes de San Fernando (1753-1831)", págs. 15-31.

" AlberTI, Lé́n Baptista: "Los Diez libros de Arquitectura de León Baptista Alberto"... Segunda edición en castellano, corregida por D. R. B. Madrid, en la Imprenta de Joseph Fraganillo, 1797,3 vols.
} 


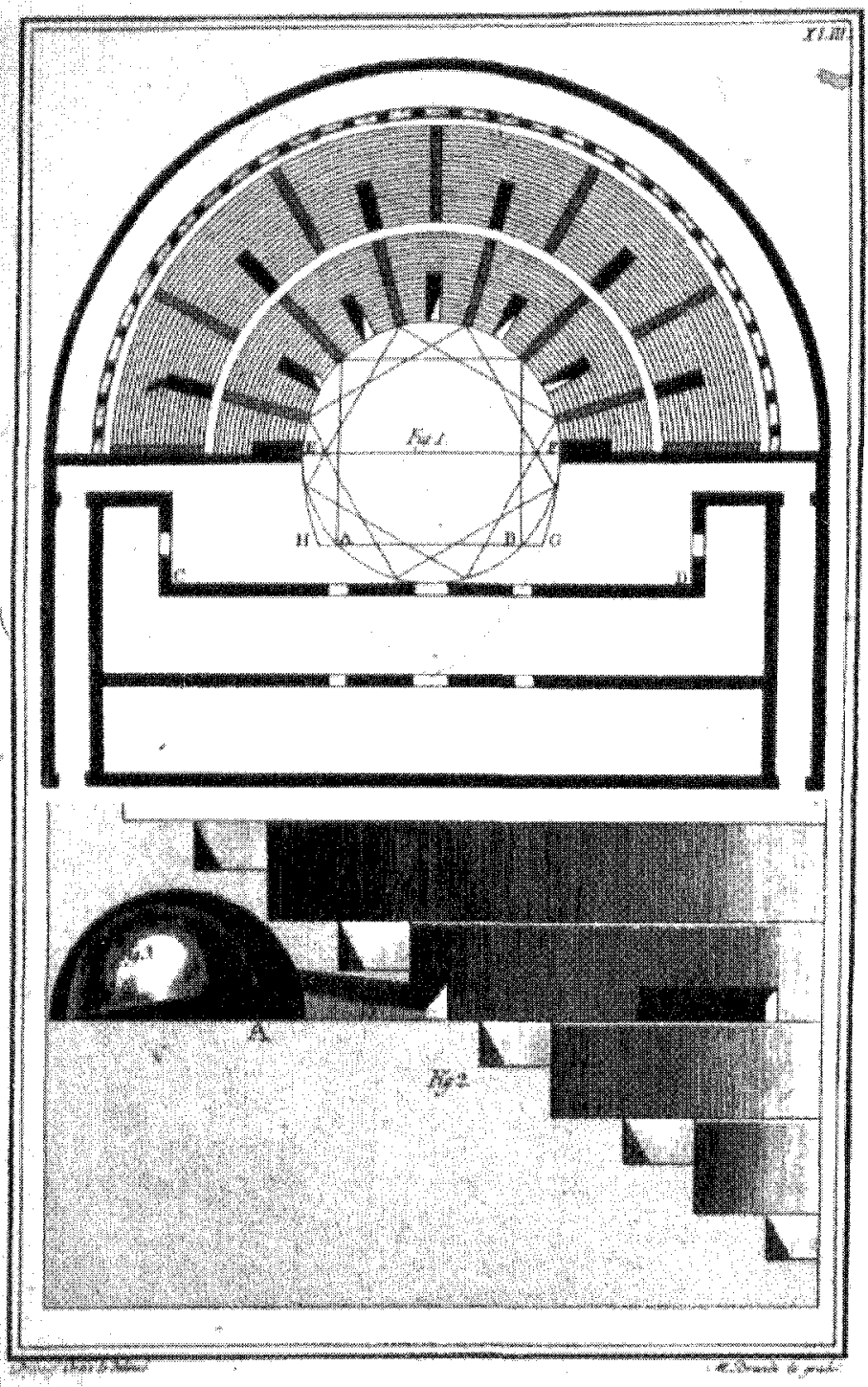

Lám. II: Teatro griego según Ortiz y Sanz. Lám. XLIII de su traducción de "Los diez libros de Architettura» de Vitruvio (Madrid, 1787). 
para espectáculos, distinguiendo según la Antigüedad, el teatro del circo y del anfiteatro. Aquel tenía una forma semicircular, «semejante a una luna menguante". Alberti proporcionó en su tratado al mismo tiempo el sistema greco-romano de construcción del teatro, basándose para ello en el estudio minucioso de los edificios, que conocia, conservados de la Antigüedad, y su opción personal como una posible alternativa. Su método se basaba en el análisis sistemático y científico de las proporciones existentes entre sus distintas partes. Deseaba, así, establecer una normativa propia de construcción del teatro con la idea de que resultara la más lograda y elogiable en todas las partes integrantes; pero reelaborándola a partir de la concepción clásica.

Pero no sólo se difundió el prototipo del teatro clásicista por medio de los tratados llegados de la Antigüedad greco-romana y de los siglos XV y XvI como los de Alberti, Serlio y de Palladio con su Teatro Olímpico de Vicenza de 1580 divulgado por Scamozzi. España se fue incorporando poco a poco o «enterándose», aunque fuera siempre de una forma algo tímida y un tanto a destiempo, a finales de la centuria de la llustración y, sobre todo, a principios del $\mathrm{x} \mid \mathrm{x}$, a los debates promovidos en Francia $\mathrm{e}$ Italia para crear una tipología teatral moderna por medio de modelos ideales, que, no obstante, siempre llegaban a nuestro país en cierta forma en algo de refilón. Se partía para lograrlo de ese clasicismo; pero dándolo unos aires racionalmente funcionalistas, con el fin de que se adecuaran a las necesidades teóricas y, sobre todo, prácticas de los nuevos tiempos.

Así, debieron llegar los ecos, a veces lejanos en el tiempo, a nuestro país de los libros franceses sobre este tema escritos por Dumont en $1764^{10}$, quien estableció un paralelo entre los planos de los teatros más bellos de Italia y de Francia, por Cochin en $1765^{11}$, por el Chevalier de Chaumont en $1769^{12}$, por el mismo Jacques-François Blondel (1705-

10 Dumont, J. P. Martin: "Paralléle des plans des plus belles salles de spectacles d'ltalie et de France». París, 1760-1770.

(Cochin, Charles Nicolás): "Project d'une salle de spectacle pour un théatre de comédie". A Londres, et se trouve à París, Chez Charles-Antoine Jombert, 1765. Edición facsímil en Genève, Minkoff M. Reprint, 1974. En la R.A.S.F. existe de este autor "Oeuvres diverses de M..., ou Recueil de quelques pieces concernant les Arts". A Paris, chez Ch. Ant. Jombert pere, 1771, 3 vols. A. 1076-58. En el vol. i, págs. 95-120 se incluye unas "Memoires, sur les Théâtres", en donde se ocupa de las reflexiones de Gainsay sobre el antiguo bâtiment, que se llamaba Palacio Real de los Duques de Orléans. Una de las salas de este palacio se dedicó a conciertos.

12 Chevalier De Chaumont, M. le: «Exposition des principes qu'on doit suivre dans l'ordonnance des théatres modernes", 1765. También de CHEVALIER DE CHAumONT: "Véritable construction d'un théâtre d'Opera, à l'usage de France, suivant les principes des Constructeurs Italiens, avec Toutes les Mesures \& Proportions relatives à la Voix, expliquée Par des Regles de Géometrie, \& 
1774) ${ }^{13}, y$, de una forma especial tal y como se verá después, por Pierre Patte (1723-1814) ya en 1782. Este arquitecto francés fue precisamente quien finalizó, en la práctica los escribió, los tres últimos volúmenes del "Cours d'Architecture" de su maestro Blondel, quien en 1743 creó una Ecole des Arts en París, que se enfrentó por su concepción pragmática a la Escuela de la Academia Francesa de Bellas Artes.

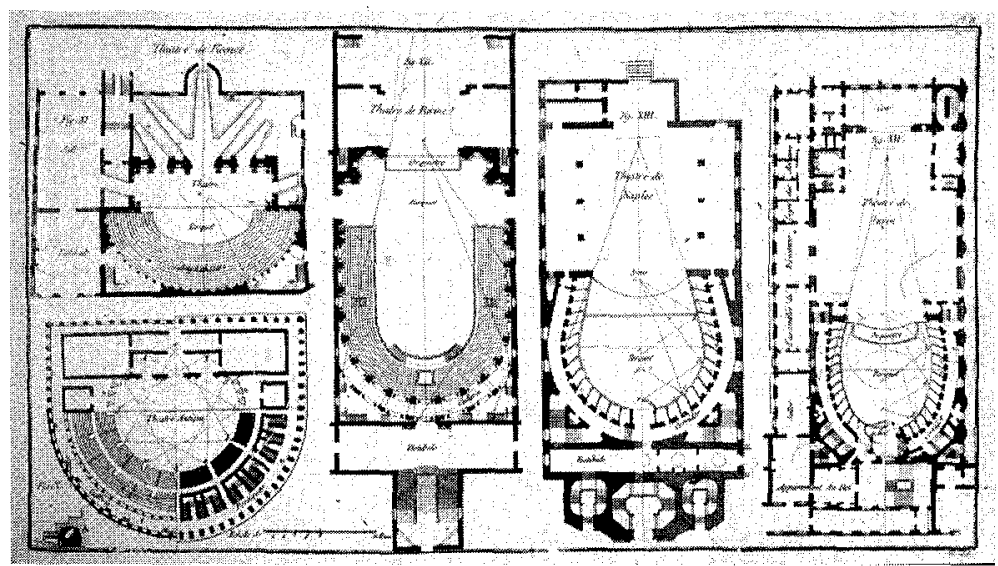

Lám. III: Distintas plantas comparativas de teatros reproducidos por Pierre Patte en su «Essai...» (1782): Teatro de Vicenza, Teatro Antiguo, Teatro de Parma, Teatro de Nápoles y Teatro de Turín. Patte propició con la publicación de estos modelos el historicismo teatral.

des Raisonnements Physiques; Secrets très important, \& qu'on découvre au Public», Par M. le Ch. de $C^{\star \star \star}, D^{* * \star}$. $J^{\star \star \star}$. París, Chez de Lormel, Imprimeur de l'Academie Royale de Musique, 1766. Edición facsímil en Genève, Minkoff M. Reprint, 1974. Un año después publicó otro folleto: "Véritable construction exterieure d'un théâtre d'Opéra, à l'usage de France, relative a celle donnée l'année derniere, pour la Construction intèrieure"... A París, Chez de Lormel, 1767.

13 BLONDEL, Jacques François: "Cours d'architecture, ou Traité de la décoration, distribution et construction des bâtiments, contenant les leçons données en 1750 et les années suivantes, par..., continué par M. Patte. París, Desaint, 1771-1777, 6 vols. de texto y 3 de láms. B.R.A.S.F.: C. 1627-1637. Los volúmenes 1, 2 y 7 de este ejemplar de la Academia tienen ex libris de Benito Bails. 
De este modo se establecía en la arquitectura francesa del último tercio del siglo XVIII un auténtico debate historicista, erudito, crítico-teórico y proyectual sobre el camino que la tipología del teatro debía seguir en el futuro. Algunos escritores, como Rousseau y el mismo Voltaire en su «Disertation sur la tragèdie ancienne e moderne» de 1748, quien criticó la falta de funcionalidad del teatro parisiense, propiciaron la controversia. Se partió siempre del análisis de los teatros más significativos por las formas de sus auditorios existentes en la misma Francia y en Italia. Tales edificios eran comparados entre sí, para lograr alcanzar un estado de la cuestión, una revisión profunda con la finalidad de hacer coherente el edificio del espectáculo con las nuevas exigencias estéticas tanto arquitectónicas como musicales y literarias, y las necesidades mundanas.

Hay que añadir a todo ello la difusión del concepto ideal divulgado por Milizia sobre esta tipología en la España de la última década del siglo XVIII. Ortiz y Sanz tradujo entonces, en concreto en $1789-$ y tan sólo dos años después de publicar su versión de Vitruvio en 1787 y antes de imprimirse su traducción de Palladio en 1797- al castellano su libro sobre el teatro una revisión actualizada del sistema clásico, pero dándola unos aires ya racionalistas y hasta funcionales, que no obstante derivaron en utopía ${ }^{14}$. La obra literaria del arquitecto italiano, que configura la forma arquitectónica teatral en todo su entorno humanístico al relacionarlo con su finalidad de recinto espacial para la literatura y la música, había sido publicada por primera vez en Roma en 1771, retirado de la venta en las librerías a los dos meses, y después se reeditaría en la Venecia de 1794.

Frente a la alternativa italiana del teatro moderno con base clásica de auditorio de planta semicircular con anfiteatro de gradas, proporcionada por Milizia, también se difundió en España la opción francesa aportada por Pierre Patte, quien en 1782 publicó en París el "Essai sur l'architecture théâtrale». Su modelo, cuyo auditorio es una elipse truncada por el lado de la orquesta y está inscrito en la primera mitad de una planta rectangular, parece el resultado de una reflexión profunda sobre la repercusión de las leyes de la óptica y de la acústica en la planta de este edificio en la

${ }_{14}$ MILIzzIA, Francesco: «El Teatro». Otura escrita en italiano por Don Francisco Milizia. Traducida al español por D. J[osé] F[rancisco] O[rtiz]. Madrid, en la Imprenta Real, 1789. La primera edición de este libro se publicó en Roma el 25 de diciembre de 1771 bajo el título de «Trattato completo, formale e materiale del Teatro". La segunda edición salió a la iuz en Venecia, nella Stamperia di Prieto Q. Gio. Batt. Pasquali, en 1794. Milizia también se ocupó de esta tipología en «Principi di Architettura civile». Finale, Nella Stamperia di Jacopo de' Rossi, 1781, 3 vols. En la segunda parte, tomo II, dedicó el capítulo XVI, págs. 426-461. 
consideración de los avances experimentados entonces por tales ciencias, sobre todo, bajo la referencia de las lecciones de Física experimental de Nollet ${ }^{15}$. La tipología teatral de Patte, que en el fondo desarrolló el proyecto para una sala de espectáculos de Cochin de 1765, quien ya lo concibió elíptica aunque transversal, obedece, así pues, a un pensamiento racionalista y funcional, tan típico de la arquitectura de la llustración francesa en las décadas finales del siglo XVIII, que, no obstante, parte siempre de una concepción clásica de la arquitectura.

La Real Academia de Bellas Artes de San Fernando adoptó conceptualmente en su arquitectura durante estos momentos las dos opciones arquitectónicas principales y vigentes en Europa de revisión del clasicismo, y ello también se manifestó en la tipología del teatro: la italiana de Milizia, promovida durante esos años, sobre todo, por Ortiz y Sanz, y la francesa de Patte, divulgada por Bails, quien prácticamente le copió, oscilando casi siempre con ciertas dudas entre ellas. Eran los dos modelos culturales posibles en una España que luchaba por incorporarse al arte internacional por medio de los dos paises principales, en los que secularmente se basaba su proyección política y cultural. Durante la segunda mitad de la centuria de la llustración Roma y París se constituyeron en los dos centros culturales más importantes en la difusión del sistema clásico y en los lugares de citas imprescindibles para los artistas. Por tal motivo la Academia envió a sus mejores discípulos a estas ciudades, y principalmente a los arquitectos a Italia, para que acabaran de formarse, concediéndoles pensiones.

La línea francesa fue promovida, sobre todo, desde mediados del siglo XVIII por Diego de Villanueva, José de Castañeda, Pedro Arnal y Benito Bails, aún con cierto eclecticismo entre lo francés y lo italiano, en los medios académicos de la Corte. Sin embargo, José Ortiz y Sanz fue uno de los principales difusores de la visión arqueologista clásica y de la opción italiana coetánea a través de sus traducciones, alternativa que había tenido a José de Hermosilla como uno de sus promotores más significativos

15 PATTE, [Pierre]: «Essai sur l'Architecture Théâtrale, ou de l'Ordonnance la plus avantageuse à une Salle de Spectacles, relativement aux principes de l'Optique et de l'Acoustique. Avec un Examen des principaux Théâtres de l'Europe, \& une Analyse des écrits les plus importans sur cette matiere", par M. Patte, Architecte de S.A.S. Mgr. le Prince Palatin, Duc regnant de DeuxPonts. París, chez Moutard, Libraire-Imprimeur de la Reine, 1782. Edición facsímil en Genève, Minkoff Reprint, 1974. También publicó «Monuments èrigès en France à la gloire de Louis XV, prècedés d'un tableau du progrès des Arts \& des Sciènces sous ce reyne». Par M. Patte. París. Imprimerie le Moreau, 1765. B.R.A.S.F.: B-2672. B.N.: 3/31.151. 


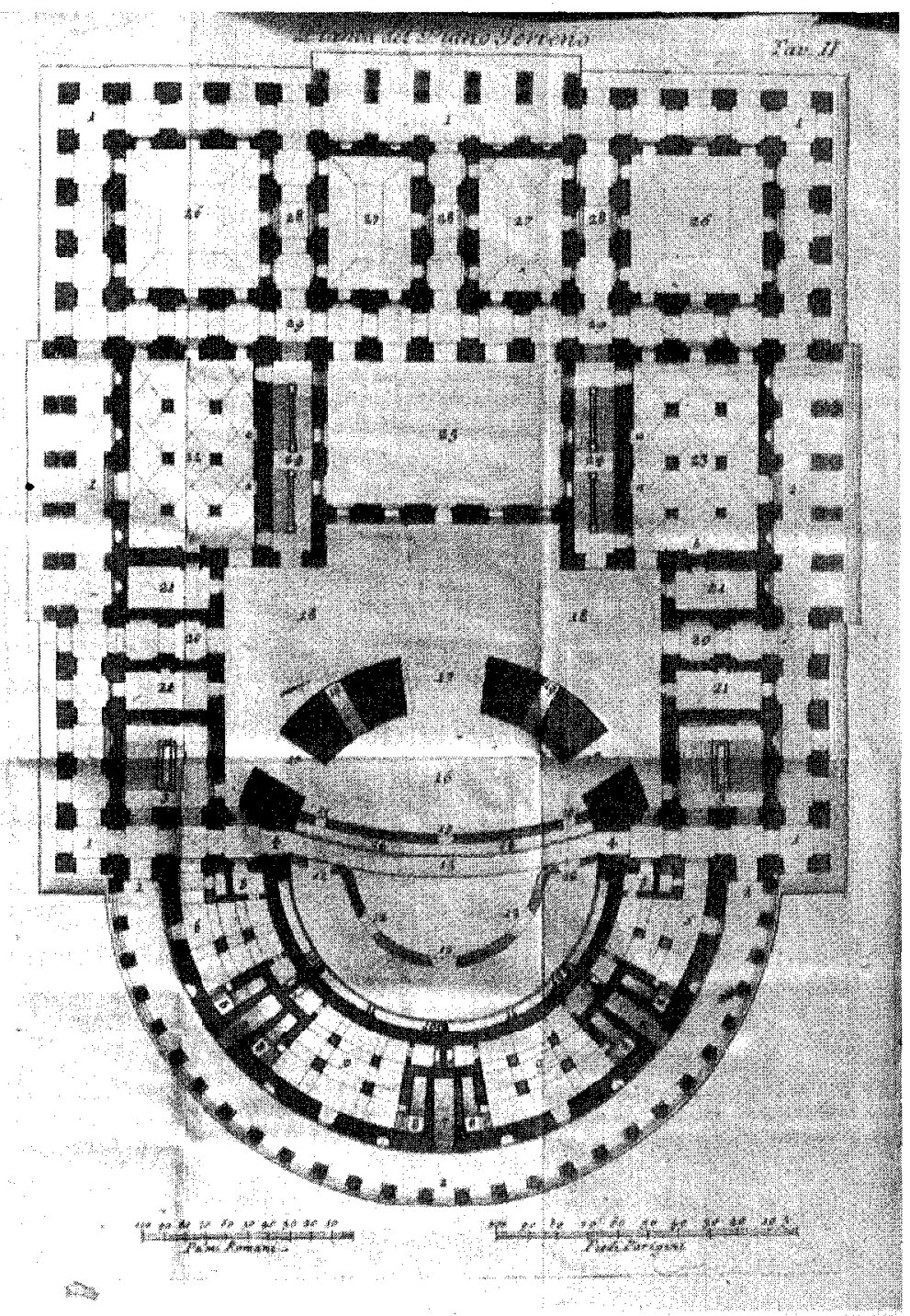

Lám. IV: Diseño de la primera planta sobre los pórticos de un edificio para teatro según Vicente Ferrarese en el libro de Milizia. 
en torno a 1750, así como a Juan de Villanueva en las décadas de los años setenta y ochenta.

No obstante, hay que tener en consideración que, aunque la Academia madrileña fuese el espejo político e institucional de la parisiense, el arquitecto español se formó sobre todo en la concepción artística italiana por medio de las pensiones en Roma. Allí estuvieron Miguel Fernández entre 1747 y 1759, Juan de Villanueva de 1758 a 1764, Manuel Martín Rodríguez en 1776, Guillermo Casanova entre 1779 y 1785, Silvestre Pérez y Evaristo del Castillo de 1791 a $1796 \ldots$.. La opción francesa se debió en gran parte a las buenas relaciones políticas y dinásticas, al conocimiento común de esa lengua en España y a la llegada de ciertos arquitectos formados en Francia, tal y como es el caso de Pedro Arnal.

Si Ortiz y Sanz promovió la opción italiana de tipología teatral al traducir en 1789 el "Teatro" de Milizia, el matemático Benito Bails difundió antes en su "Tratado de arquitectura civil» la alternativa francesa de Patte, que refleja fielmente, hasta ser la mayoría de las veces una simple traducción suya casi literal, en este libro muy ecléctico, en la práctica una antología de textos sobre todo franceses, publicado un año después que la obra francesa, en 1783. Así, pasó a parecer ser un modelo de su propia invención, pues apenas le cita ${ }^{16}$.

Bails al divulgar literalmente en España la planta teatral de Patte proyectó esta tipología hacia el siglo XIX, dotándola de ciertos aires de modernidad; pero alejándose del código clásico. El espacio elíptico de la planta de su auditorio obedecía a un estudio de la óptica y, sobre todo, de la acústica ya bien moderno. La opción se hallaba en la misma línea conceptual de dar a la arquitectura una base más científica que dibujística promovida por el propio Bails y Antonio de Varas, los profesores de Matemáticas en la Academia. Se buscaba la adaptación del auditorio a los sentidos de la vista y del oido, funcionalidad ya existente en los teatros de la Antigüedad, pero ahora revisada con los nuevos adelantos científicos experimentados en esas disciplinas. Pero así, sembró de dudas a la Academia ante una opción tan alejada del semicírculo clasicista y en algo más pragmática, menos utópica, que la de Milizia. La propuesta distaba

16 BAILs, Benito: "Elementos de Matemáticas", por D. Benito Bails... Tomo IX. Parte I. Que trata de la Arquitectura civil. Segunda edición corregida por el autor. Madrid. En la Imprenta de la Viuda de D. Joaquín Ibarra, 1796. Véase el interesante estudio de Joaquín Navascués Palacios sobre este libro, publicado como tomo primero de la edición facsímil del Colegio Oficial de Aparejadores y Arquitectos Técnicos de Murcia de 1983. Dedica a la tipología del teatro aportada por Bails las páginas 120-130, el epígrafe titulado «Bails y el modelo teatral de Patte». 
también de las alternativas vigentes en España de auditorio en $U$ y de herradura, a la italiana, procedentes de Juvarra y del ingeniero militar español Medrano en San Carlos de Nápoles.

Los tratados sobre la arquitectura teatral y la biblioteca de la Academia

No obstante, a pesar de la difusión en España de los libros de Milizia y de Patte realizada respectivamente por Ortiz y Sanz, y Bails, no es posible de momento determinar con exactitud total hasta qué punto se conoció en nuestro país el alcance del debate sobre el teatro acaecido en Italia y Francia en las décadas de los años sesenta, setenta y ochenta dél siglo XVIII. El estudio de los fondos de la biblioteca de la Real Academia de Bellas Artes de San Fernando es en su conjunto negativamente revelador, aunque se localicen algunas de las propuestas de la época. Pero las consecuencias obtenidas de su análisis no pueden ser consideradas definitivas hasta que no se conozcan con exactitud los libros poseidos por los profesores arquitectos en sus librerías privadas o vistos por ellos en sus viajes europeos.

Es significativo, por ejemplo, que en el primer índice de libros existentes en la biblioteca de la Academia realizado por Pascual y Colomer en 1794 o 1795 no se hallaran determinadas publicaciones ${ }^{17}$. Así, de Patte no estaba en este inventario, añadido posteriormente ya en 1826 con doscientas diez papeletas de obras adquiridas después por el bibliotecario José Franco, su sucesor, su "Essai sur l'architecture théâtrale» de 1782. Tal ausencia quizás fuera el motivo que llevó a Bails a copiarlo casi literalmente en su «Arquitectura civil» (1796) a la hora de referirse a la tipología del teatro. Prescindió de sus comentarios eruditos bibliográficos y del estudio comparativo de una serie de teatros franceses e italianos, partes importantes por el elemento crítico, erudito e historicista, que aportan. Es posible que pensara que los arquitectos de la Academia ignoraban su existencia. De Patte se hallaban entonces, sin embargo, otros tres libros en la biblioteca madrileña: «Monuments èrigès en Fiance à la gloire de Louis XV» (París, 1765), "Memoires sur les objets les plus importants de l' Architecture» (París, 1769) y su continuación del "Cours d'Architecture» de Blondel.

\footnotetext{
17 «Indice de los libros que existen en la biblioteca de la Real Academia de San Fernando". Este índice lo realizó el primer bibliotecario de la Academia, JUAN PASCUAL y COLOMER hacia 1794 ó 1795. Fue añadido posteriormente en 1826 por su sucesor JosÉ Franco con 210 papeletas de obras adquiridas después. A.A.S.F.: $71 / 3$.
} 
El estudio de Martín Dumont titulado "Parallèle de plans des plus belles salles de spectacles d'Italie et France" de 1764 ni se halla ahora ni tampoco estaba entonces en la biblioteca de la Academia. En él publicó su proyecto de hacia 1760 para una sala de conciertos bastante innovador. La planta general es rectangular, pero en ella inscribió un cuadrado. Entre ambas figuras situó una sala de recepción, dos corredores laterales y la entrada. A su vez inscribió en ese cuadrado un círculo, en el cual dispuso un anfiteatro, el parterre en medio avanzado sobre él y la orquesta detrás.

Sin embargo, en esta librería se localiza un interesante "Album de proyectos y planos" de Dumont, posiblemente posterior a 1767, en donde hay varias láminas dedicadas a los edificios para espectáculos. En el proyecto para un belveder, un cazín italiano o palacio campestre, incluyó dos salas en el centro mismo del edificio, teniendo así un sentido simbólico, la una para salón de música a la italiana de planta totalmente circular y la otra destinada a teatro oval. Pero, además, hay un plano para sala de espectáculo, cuyo interés reside en la forma oval del auditorio en anfiteatro de gradas, patio y un proscenio trapecioidal circular, que relaciona la ovalidad de la parte dedicada a los espectadores con el rectángulo de ángulos curvos del escenario. Es, sin duda, un proyecto que contradice su primera propuesta de 1764, que, sin embargo, se halla presente en el salón de música del belveder ${ }^{18}$.

Nada hay de Chaumont. Tampoco se hallaban en esta librería académica el «Projet d'une salle de spectacles pour un théatre de Comédie» de Charles Nicolás Cochin publicado en 1765 . Es posible que los arquitectos de formación francesa como Pedro Arnal o el propio matemático Bails lo conocieran, pero no consta ni en el inventario de Juan Pascual y Colomer ni entre los fondos hoy existentes. Sin embargo, se localiza en ella un libro posterior suyo, de 1771, con el título de «Oeuvres diverses». Cochin incluyó en el volúmen I unas "Memoires sur les Théâtres», en donde se ocupó de las reflexiones de Gairsay sobre el antiguo bâtiment, que llamaba Palacio Real de los Duques de Orléans. En esta casa de placer había una sala llamada de conciertos. De Cochin también estaba su libro describiendo su viaje a Italia publicado en 1758.

Tampoco se localizan en el inventario de la biblioteca de la Academia madrileña, realizado por Juan Pascual y Colomer ni en las adiciones de Franco, libros clásicos italianos sobre el teatro, como, por ejemplo, «De

18 Dumont, MARTín: «Proyectos y planos». (S.l., s.a.). B.A.S.F.: B-1894. El álbum es posterior a 1767, pues el retrato incluido del arquitecto fue dibujado por KUCHARSKI y grabado por BARÓN de un cuadro de Moreau de ese año. Los proyectos de DumONT fueron grabados por CHARPENTIER. 
perspectiva de' picttori e architetti» (1693) de Pozzo, ni el «Trattato sopra la struttura de' teatri e scene» (Mantua, 1676) de Carini Mota. La «ldea di un teatro... simile a' teatri antichi» (1762) de Eneas Arnaldi no está en la biblioteca, pero fue conocida a través de la segunda edición del libro de Milizia.

No obstante, se halla el "Saggio sopra l' Opera in Musica» del Conde Francisco Algarotti, aunque formando parte de la "Opere" publicada en Livorno entre 1765 y 1766 en ocho volúmenes. El libro había salido a la luz en esta ciudad en 1762. Su reseña se añadió a este inventario ya en 1826 por José Franco ${ }^{19}$. El auditorio más apto para Algarotti era el semielíptico longitudinal truncado. Sin embargo, partió en su propuesta del teatro semicircular a ejemplo de los antiguos, después de caricaturizar los razonamientos, en los que se basaba la opción en forma de campana, y de negar su valor acústico por estrecharse demasiado la platea y hacer perder a muchos palcos la vista del escenario.

La razón de tal preferencia se halla en que de todas las figuras de un perímetro igual, el círculo encierra más espacio. Además, los espectadores situados en su contorno están todos vueltos hacia la escena, de modo que ven en su totalidad $y$ entienden igualmente en cualquier sitio que estén, por hallarse equidistantes del centro. Pero veía en esta figura un defecto inevitable para ser empleada como planta de auditorio en los teatros modernos: da una abertura muy grande a la embocadura de la escena o ia luz del escenario. Por tal causa propuso el empleo de la semielípse longitudinal, que la dotaba de menos anchura y de una mayor longitud a la sala. Así, su eje menor servía de luz al palcoescenario y el mayor para la longitud de la platea. Patte se inspiró, por tanto, además de en otros autores franceses, en Algarotti, al que reseña en su libro, al elegir su opción de auditorio elíptico, y, además, la biblioteca de la Academia poseía este estudio del italiano.

LOS MODELOS "CONSTRUIDOS»Y LOS PROYECTADOS PERO IRREALIZADOS EN LA FORMULACIÓN ACADEMICA DE LA TIPOLOGÍA TEATRAL

Todas estas referencias escritas, en las que el pasado y el presente parecen encontrarse laberínticamente en un afán libresco común clasicista

19 Algarotti, CONTE: «Opere», del... Livorno, MaRco Coltellini, 1764-65. 8 tomos. El «Saggio sopra l'Opera in Musica" forma parte del tomo II, págs. 251-327, y su dedicatoria está fechada en Pisa el 18 de diciembre de 1762. 
casi utópico, debieron influir, concurriendo, en el simple deseo, más conceptual que realizable, de configurar una tipología teatral ideal y universal a finales del siglo XVIII en el medio académico. Pero la aspiración al parecer nunca se llevó a la práctica ni aún sobre el papel, a excepción del diseño de teatro aportado bastantes décadas antes por José de Hermosilla en 1750 , en la España de finales de la llustración.

La Academia parecía oscilar entre la cita histórica clásica erudita vitruviana, ya tan sólo realizable de un modo referencial, la renacentista de Alberti y de Palladio, y los modelos del presente italianos y franceses, su reelaboración. Así pues, existía por pura necesidad un deseo funcional y ecléctico de adecuar las necesidades concretas de aquel hoy a las líneas maestras de ese ayer paradigmático. Quizás todo ello $-\mathrm{y}$ aún también la existencia de opciones racionalizadas científicamente, que no eran clásicas en un sentido estricto, como la de Patte, pero sí metódicas, ilustradas y funcionales - obligó a este centro a no establecer nunca de forma oficial una sola opción o un modelo único e inamovible durante la segunda mitad del siglo XVIII. Se prefirió proponer con estudiada ambigüedad ciertos ejemplos elaborados en la Europa de la llustración en base a las alternativas barrocas con alguna referencia a la Antigüedad; es decir, una serie de modelos, unificados bajo las normas permanentes vitruvianas en algo abstractas y con el afán de simplicidad y desornamentación, normas que no estaban reñidas con el de la necesaria buena economía y hasta con su funcionalidad, tan precisas entonces.

Sin embargo, hubo otros "ejemplos vivos" en los teatros que, sobre todo, desde el segundo tercio de esa centuria se realizaron en Madrid y su entorno cortesano, distinguiéndose entre los construidos de nueva planta y las remodelaciones ${ }^{20}$. Estos modelos de edificios realizados, o hasta a veces proyectados y no construidos, también debieron pesar más o menos consciente o inconscientemente a la hora de diseñar, o tratar de hacerlo, una tipología académica del teatro.

Aquellos se edificaron en estrecha vinculación con los palacios reales en los lugares de residencia de la Corte, configurando un aspecto más, pero importante de la arquitectura cortesana, y hasta del urbanismo, en Aranjuez, El Pardo, El Escorial, San Ildefonso y el Retiro durante los reinados de Felipe $v$ y de sus hijos Fernando vi y Carlos III. Fueron obras

20 Sobre los teatros madrileños es fundamental el libro: FeRnández Muñoz, ANGEL LUIS: "Arquitectura teatral en Madrid. Del corral de comedias al cinematógrafo». Madrid, Ed. Ayuntamiento de Madrid - Avapiés, 1988. Incluye un prólogo de Pedro Navascués Palacio. 
hechas o proyectos irrealizados de arquitectos extranjeros, especialmente italianos por su número, llamados y llegados a España con la idea de internacionalizar las construcciones reales, adecuándolas a lo que se hacía en los paises más cultos de Europa, como Santiago Bonavía, entre 1738 y 1750, Galuzzi, Juvarra y Sacchetti. Los italianos, y especialmente Juvarra, demostraron sus grandes dotes para la escenografía. Este arquitecto diseñó un proyecto de teatro con la finalidad de que sirviera de sustituto del Corral de la Cruz ${ }^{21}$, mientras que su discípulo Sacchetti propuso la construcción de un coliseo o Teatro de la Corte junto al nuevo palacio real madrileño, que no se realizaría.

Pero no faltó la opción francesa presente, al menos en la nacionalidad de su autor, con Jaime Marquet, quién diseñó los planos y se encargó de la dirección del Teatro de Aranjuez de 1767, del Teatro Real de El Escorial y del nuevo Teatro de El Pardo proyectados ambos en 1770, que se concluyeron en 1778. Este último sería ampliado y reformado por Isidro González Velázquez ya en $1826^{22}$. Tal y como se ha señalado ${ }^{23}$, también intervino en la realización del que se construyó en la Granja y en la conservación del Coliseo del Buen Retiro, que había sido remodelado por Bonavía, pudiéndose considerar como el principal arquitecto especialista en esta tipología entre 1770 y 1782, año en el cual falleció.

Se producía, así, la penetración en nuestro país por la vía de la práctica arquitectónica, y no sólo por la teoría, de la alternativa de la tipología teatral cubierta presente en Europa. Es posible deducir aquí con la idea de generalizar que, si el sistema italiano predominó en las construcciones de teatros o de sus proyectos irrealizados y escenografías en España entre 1737 y 1770, desde esta fecha hasta ese año de 1782 sería la opción francesa italianizante la preferida a la hora de construir este tipo de edificios.

No obstante, la planta siguió siendo la clásica semicircular del lado del espectador, cuyos extremos se prolongan en línea recta, muchas veces

21 Fernandez, L.: "Proyecto de FIllippo Juvarra para un teatro de Madrid". "Villa de Madrid", núm. 83, 1985-1, pág. 47

22 Navascués Palacio, Pedro, "Los discípulos de Villanueva». En el libro «Juan de Villanueva, arquitecto (1739-1811)». Madrid, Delegación de Cultura del Ayuntamiento de Madrid, 1982. Véase la pág. 82. También Moreno VILLA, J.: «Proyectos y obras de don ISIDRO VELÁzQUEZ. Sus trabajos en El Pardo". "Arquitectura», 1932, núm. 155, págs. 69-76.

23 Un importante estudio sobre la arquitectura teatral en España durante el siglo XVIII es el siguiente: Tovar Martín, VIRGINIA, "Teatro y espectáculo en la Corte de España en el siglo XVIII». En "El Real Sitio de Aranjuez y el Arte Cortesano del Siglo Xvil", págs. 221-239. (Madrid) Comunidad de Madrid - Patrimonio Nacional, 1987. 
peraltada, o se cierran en forma de herradura, mientras que el escenario es rectangular. Está aún alejada, por lo tanto, de la opción elíptica de Patte. Ambos espacios formalmente diferenciados entre sí, pero interdependientes en su conjunto, como lugares el uno estático y, sin embargo, receptivo expreso en toda su curvatura, y el otro dinámico, sitio de la acción encerrada por contraste en un receptáculo un tanto falto de movimiento de ángulos rectos, se inscriben dentro de un rectángulo. Esto ocurre, como ejemplos significativos, en los Teatros de Aranjuez y de El Escorial; pero, en el del Pardo, remodelado ya en 1808 por Isidro González Velázquez, los espacios parecen confundirse, siendo semicircular el palco dedicado al rey, sitio referencial y espectacular dentro del espectáculo, el lugar de la realeza, mientras que el auditorio y el escenario se desarrollan en un rectángulo.

Las normas de la simetría y de la perspectiva, exigibles por las necesidades ópticas de esta clase de edificios, desempeñan un papel fundamental en la composición de la tipología del teatro. Realizan la función de coordenadas arquitectónicas principales y establecen un nexo imprescindible con el sistema clásico de base científica. La forma curva del coliseo para los espectadores se contrapone al rectángulo del escenario, constituyendo un dualismo perfecto y esencial en la configuración del teatro. La curva, reflejo de las dinámicas ondas sónicas, contribuye a retener los sonidos y a envolver al público, recogiéndole en un ambiente estático e inactivo propio, que visualmente y por medio también de los efectos de la iluminación se dirige hacia el escenario, en donde se realiza la acción. EI sistema de distribución de los asientos en esa curva, asimismo, contribuye a realizar una estratificación jerárquica de los espectadores siempre en función de la mayor o menor altura y del centro o colateralidad visual y acústica de la perspectiva con relación a ese escenario.

Este teatro cortesano de carácter eminentemente privado presenta unas dimensiones bastante reducidas. Hay un equilibrio estable entre los espacios dedicados al espectáculo y al público, que en un número siempre escaso acudía a ver la obra. El escenario debía acomodar el tamaño de su superficie útil a la colocación de las decoraciones cambiantes en un período durante el cual la escenografía adquirió una gran importancia ${ }^{24}$. Pero el concepto educativo del teatro, propiciado durante esa elitista llustración al comprobarse de una forma vitalista el utilitarismo de la enseñanza del

24 Sobre la escenografía de los siglos XVIII y XIX en España es básico el estudio de ARIAS DE Cossio, Ana María: «Dos siglos de escenografía en Madrid». Prólogo de Jesús Hernández Perera. Madrid, Mondadori, 1991. 
pueblo para mejorar la economía general, generó la transformación de su privacidad hacia lo público. Por este motivo la sala tuvo que ampliarse considerablemente para recibir más espectadores. Y con la ampliación se jerarquizó en diferentes espacios destinados a personas de distintas condiciones sociales y entre ellas de la naciente burguesía. Se romperá con las proporciones espaciales equilibradas del teatro cortesano entre el escenario y el patio, para que en este último sitio tuviera cabida mucho más público.

Pero, además de las diferencias formales existentes entre las arquitecturas de las viejas corralas y los teatros cortesanos con sus peculiaridades en sus respectivas configuraciones arquitectónicas en España, hay otra distinción importante derivada de sus propias finalidades. Así, mientras en áquellas se celebraban, sobre todo, espectáculos teatrales basados en el realismo de la palabra con las representaciones de comedias y tragedias de la literatura española del siglo de Oro, que en ocasiones también incluían músicas folklóricas, en los teatros cortesanos tenían lugar acontecimientos musicales más elitistas como conciertos y óperas. El pueblo se sentía más reflejado por estas obras teatrales del barroco, por ejemplo de un Lope de Vega o Calderón, que entendía mucho mejor que la música culta propia de una minoría cortesana, promovida en la España de los primeros Borbones por Doménico Scarlatti durante su estancia en el Reino entre 1729 y 1757 , que les distinguía. Se enfrentaba, así, la concepción popular del espectáculo con raíces en el siglo XVII con el refinado intelectualismo cortesano musical mucho más cosmopolita y en algo más abstracto durante la llustración. Y en este sentido existían dos tipos arquitectónicos diferentes por su función de edificios teatrales con unas directrices generales comunes en cada uno y, asimismo, entre ellos, que se materializaban en distintos modelos.

Las transformaciones de viejas corralas barrocas con la idea de integrarlas en el sistema arquitectónico teatral internacional afectaron a los teatros de la Cruz, del Príncipe y de Caños del Peral. Similares a las casas de vecinos poseían un patio central descubierto generalmente de planta rectangular. Este último, en cuyo solar se levantó el actual Teatro Real, fue reformado al estilo italiano por Jácome Bonavía y Juan Bautista Galuzzi en 1737, aunque conservó algunas partes de la forma antigua. En 1787 estaba ya ruinoso, siendo demolido en $1817^{25}$.

25 BONET CORREA, ANTONIO: «Utopía y realidad en la Arquitectura». En «Doménico Scarlatti en España", págs. 19-82. Madrid, Instituto Nacional de las Artes Escénicas y de la Música del Ministerio de Cultura, 1985. Véase págs. 68-69. 
En 1735 Juvarra diseñó un proyecto irrealizado para sustituir al antiguo Corral de la Cruz por un teatro nuevo a la manera barroca italiana. Su planta es de herradura disponiéndo de cinco órdenes o pisos de filas de palcos. La fachada principal tiene forma convexa, comunicando sus cinco puertas con tres vestíbulos. Su idea se conserva gracias a una copia realizada del original por Manuel Martín Rodríguez en 1785, lo cual certifica el interés que este modelo produjo en los medios académicos. No obstante, sería posteriormente remodelado en 1784 por Juan Pedro Arnal, arquitecto formado en Francia, quien diseñó el receptáculo para los espectadores en forma de herradura, respetando el sistema del proyecto de Juvarra, con un exterior desornamentado.

Sin embargo, cuando Filippo Juvarra llegó a España había ya realizado otros teatros en Italia. Hizo el proyecto del teatro Ottoboni en el Palazzo della Cancellería de Roma entre 1708 y $1711^{26}$. Pero en esta obra la planta del auditorio es de forma en U. No obstante, en el proyecto para el Teatro Regio de Turín de Benedetto Alfieri, al parecer inspirado en otro del propio Juvarra, se adopta la planta de herradura ${ }^{27}$.

Se puede deducir: así pues, que este tipo de planta en forma de herradura, a la italiana, fue bien acogido en los medios académicos, tal y como lo demuestra el hecho mismo de ser empleado por algunos de los profesores más distinguidos de la Academia, como Pedro Arnal y Manuel Martín Rodríguez, a través siempre de Juvarra.

Es muy posible que esta planta de herradura tuviera, además, aunque ahora oval, otra referencia internacional importante y hasta simbólica en el teatro de San Carlos de Nápoles, que se construyó durante el reinado de Carlos III en el Reino unificado de Nápoles y de Sicilia. Fue proyectado por el ingeniero militar español Juan Antonio Medrano -italianizándole después Milizia al Ilamarle Giovanni Metrano- realizado por Angelo Caresale, y se inauguró en $1737^{28}$

26 Sobre JuVARRA véase el catálogo de la exposición «FILIPPO JUVARRA 1678-1736». De Mesina al Palacio Real de Madrid. Salones de Génova. Palacio Real de Madrid. Abril-julio de 1994. Madrid, Electa, 1994. Comisarios de la exposición: Antonio Bonet Correa y Beatriz Blasco ESQUIVIAS.

27 Ricci, Giuliana: «Teatri d'Italia delle Magna Grecia all'Ottocento». Milano, Bramante Editrice, 1971, pág. 157.

28 Eugenio Llaguno, con las adiciones de Ceán, se ocuparon de Juan Medrano en las "Noticias de los arquitectos y arquitectura en España desde su restauración". Madrid, Imprenta Real, 1829. Se refieren a este ingeniero militar en el capítulo 111 del tomo Ix en estos términos: «En el mismo año de 1737 en que Sachetti, italiano, abría las zanjas para construir el palacio nuevo de Madrid, D. Juan Medrano, español, trazaba y comenzaba otro gran edificio en Italia. Tal es el trastorno de las cosas humanas, y la manía de buscar en los paises extranjeros lo bueno que cada 


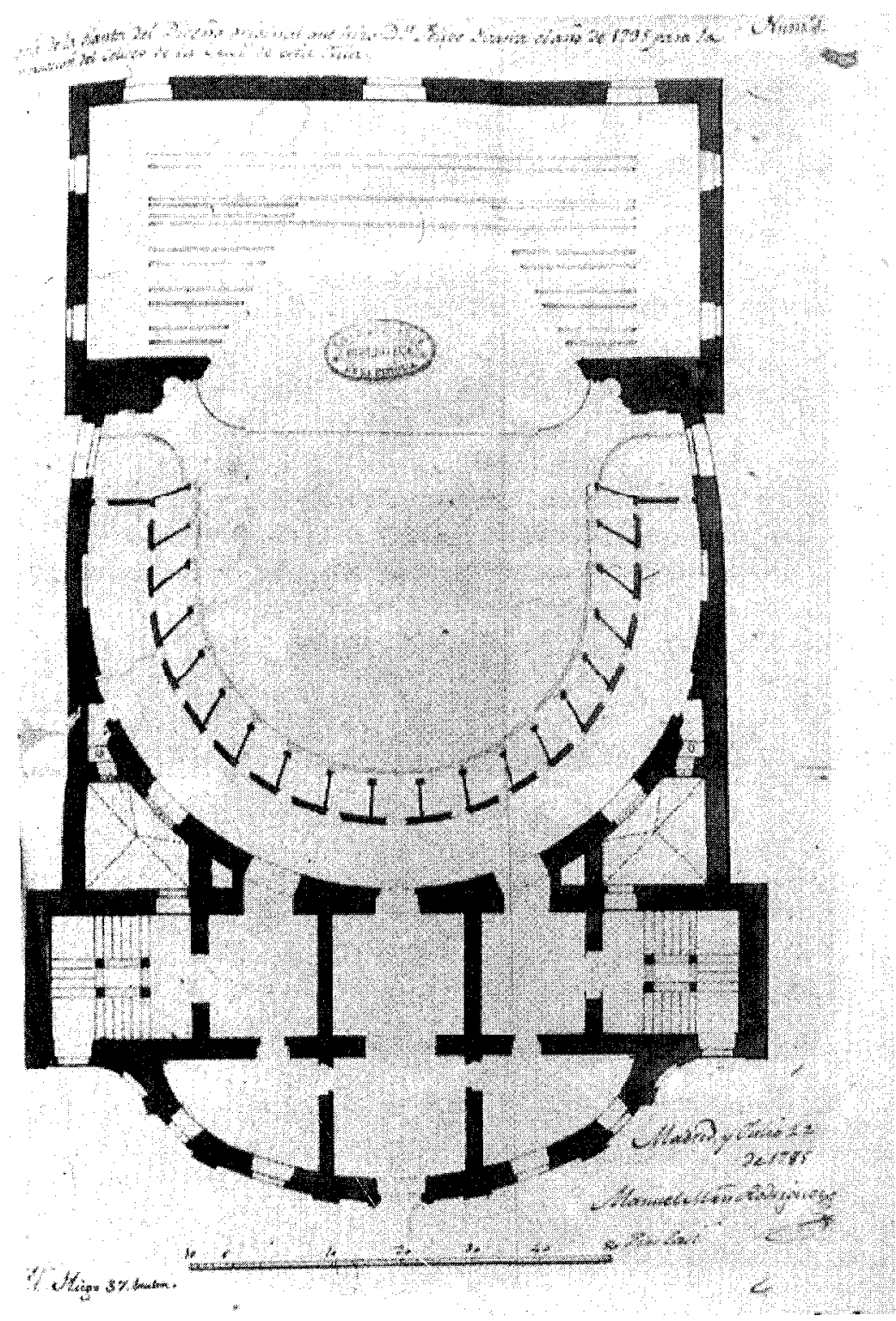

Lám. V: Copia de 1785 por el arquitecto académico Manuel Martín Rodriguez del proyecto original irrealizado de JUVARRA de 1735 de un teatro para sustituir el coliseo del antiguo corral de la Cruz de Madrid. Auditorio en forma de herradura., 
¿Habría alguna conexión entre el proyecto de Juvarra de 1735 y esta realización napolitana concluida dos años después? ¿Hallaron ambos su inspiración en el modelo ofrecido por el teatro veneciano de San Juan y San Pablo, reedificado por Carlo Fontana en 1654, que pasó a ser un prototipo de teatro a la italiana? Este edificio y el diseño de Juvarra coinciden en el número de filas de palcos: cinco pisos. Hay que tener en consideración que el teatro de San Carlos de Nápoles pasaba por ser cuando se construyó, como el más grande y hasta el más pomposo de todos los europeos. No es, así pues, increible que esta opción gozara de cierto favor en los medios académicos, tan vinculados con la trayectoria italiana de arquitectura.

José de Hermosilla confirmó este modelo de teatro de auditorio de herradura en 1750 en su magnífico diseño incluido en el manuscrito realizado durante su pensión en Roma para un texto académico de Arquitectura civil, que desgraciadamente no se publicó en la Academia ${ }^{29}$. Su propuesta enlaza con Juvarra y el teatro de San Carlos de Nápoles. De planta general rectangular, dividida por la orquesta en dos partes iguales cuadradas, destinadas la una al escenario con bastidores y la otra a cobijar al espectador, el auditorio adopta la forma italiana de herradura, circundado por un corredor con patio, pequeñas gradas en su perímetro y palcos. Tiene tres puertas de acceso: dos a ambos lados de la orquesta y la principal al fondo del auditorio, tras de un vestíbulo. Las escaleras de subida a los palcos se disponen en los ángulos de la fachada principal.

Hermosilla no analizó en el texto su propuesta de planta para el auditorio, sino que hizo breves anotaciones generales. Se refirió, así, a sus diferentes partes: escenario o escena o tablado, a la orquesta, a la platea o patio y a los palcos. Aludió al teatro greco-romano y, algo más extensamente al existente en la España de la época. Las bases de su discurso inicial erudito e historicista se hallan en Vitruvio y en Perrault, y en las ruinas del teatro Marcelo y del anfiteatro Flavio. Pero partió pragmáticamente de la idea de que los edificios para espectáculos de su época «nada tienen

uno tiene en el suyo. (...) La fama de este teatro acredita sobradamente a su autor para probar que la Corte de Madrid pudiera aprovecharse de sus conocimientos y buen gusto en la Arquitectura, sin necesidad de mendigarlos fuera del reino. Cuán útil y conveniente hubiera sido el haber encargado a Medrano construir otro teatro en esta Corte, aunque no tan costoso y magnífico como el de Nápoles, que fuese más cómodo, más decente que los que había en ella, llamadas corrales, no sé si por su origen o por su forma".

29 Delfín Rodfíguez Ruiz dió a conocer, y ahora prepara una edición facsimil, el manuscrito de Hermosilla conservado en la Biblioteca Nacional de Madrid, en «De la utopía a la Academia: El tratado de arquitectura civil de JOSÉ DE HERMOSILLA». «Fragmentos», núm., 3. Madrid, 1984, págs. 57-80. 


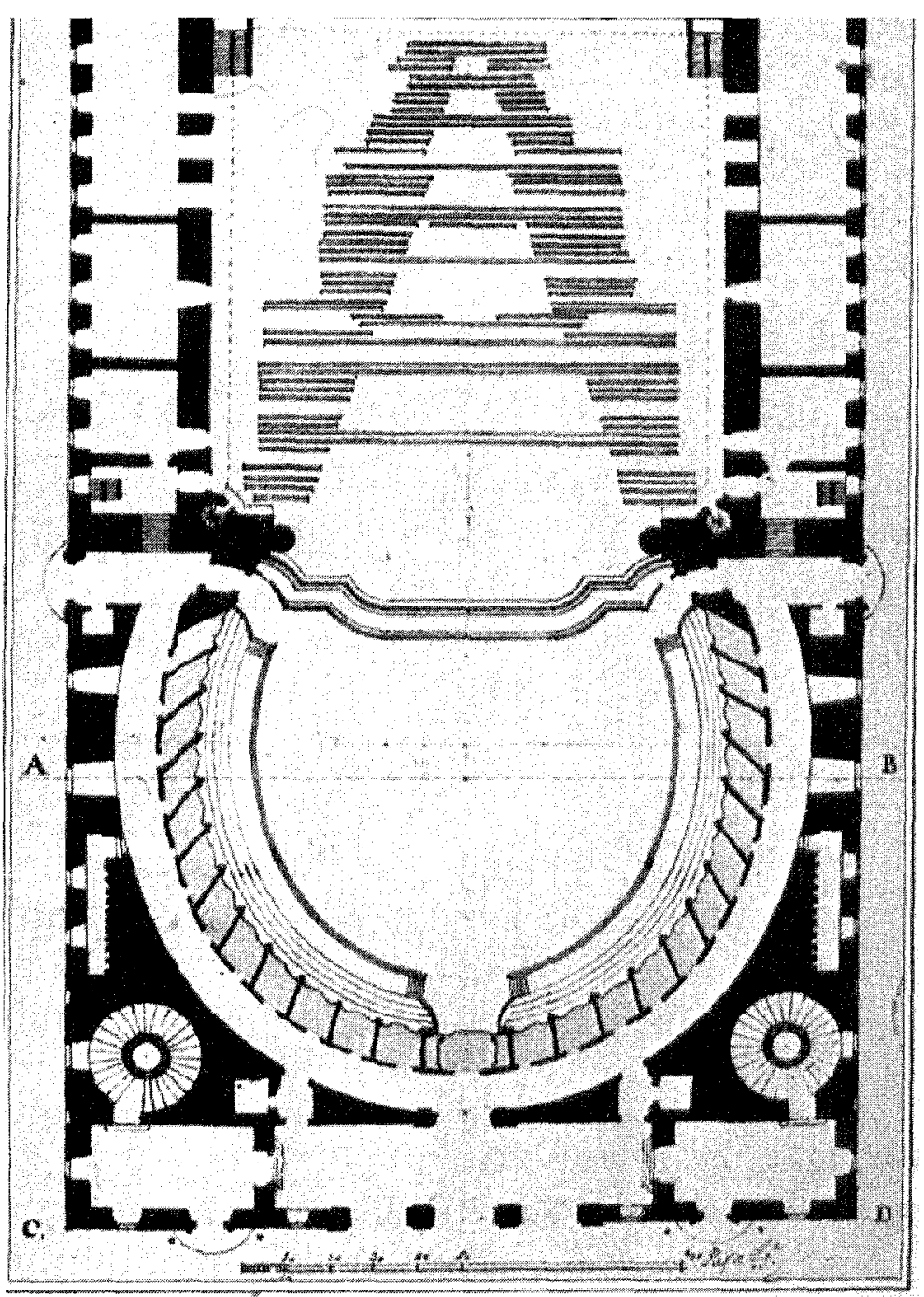

Lám. VI: Proyecto de teatro de 1750 realizado por JOSÉ DE HERMOSILLA en su manuscrito inédito "Tratado de arquitectura civil", realizado durante su pensión en Roma para la Academia. Adopta la forma de auditorio "a la italiana" de herradura en la línea del proyecto de JUVARRA de 1735 para el Corral de la Cruz y de la planta del teatro de San Carlos de Nápoles del ingeniero militar español Medrano, inaugurado en 1737. 
en común a los de la Antigüedad». Por ello se refirió a las distintas formas, circulares, elípticas y hasta oblongas, de los teatros existentes en Roma.

La otra alternativa, que fue aceptada en los medios académicos madrileños es la del auditorio en forma de $U$, el sistema propuesto por Aleotti en su teatro Farnese de Parma, realizado entre 1618 y 1628 , que incorpora ya el uso de los bastidores. Modelo que el propio Fontana después desarrolló en su segundo proyecto, construido pocos años más tarde renovado, luego de retractarse de su primer diseño oval truncado, para el teatro Tordinona de 1671. Juvarra también propició este diseño en alguno de sus proyectos, como el del teatro para el Cardenal Ottoboni, aunque onduló la planta en $U$ en su parte interior para realzar la visión desde los palcos, dotándo a su propuesta, tal vez, de resabios salomónicos.

No es extraño, pues, que Juan Milla obtuviera en 1772 el segundo premio de segunda clase de la Academia madrileña por el diseño de un teatro de comedias españolas de piedra y ladrillo, realizado en planta, fachada y corte ${ }^{30}$. Su proyecto, que se inscribe en un rectángulo, la planta general, presenta señales inequívocas de clasicismo, pues su auditorio obedece más al sistema en U del teatro Farnese de Aleotti que al proyecto final de elipse truncada de Carlo Fontana de 1695 para el teatro Tordinona. La principal originalidad está en la ruptura de las gradas por la parte central de la curva para dar cabida a tres entradas de acceso al patio, formando así una planta de campana interior, inscrita en esa $U$, que enlaza curiosamente el programa clásico-manierista con la propuesta rococó de los Galli Bibiena. Su clasicismo se halla presente también en el uso de los graderíos, emulando el sistema greco-romano. La curva del escenario se encuentra en la orquesta y el proscenio con un escenario cuadrado rodeado de habitáculos y tras de una entrada para cómicos y personal del teatro.

Por consiguiente, en la Academia no parece que se rechazase durante el transcurso de las tres últimas décadas del siglo de la llustración ni el sistema semicircular de tradición clásica, promovido de nuevo por Milizia, ni el de herradura como derivación suya, traido por Juvarra y la influencia napolitana, y asumido por Manuel Martín Rodríguez y Pedro Arnal, ni el de

30 El dibujo de MLLA se incluye en el catálogo de la exposición: "Hacia una nueva idea de la Arquitectura". Premios generales de Arquitectura de la Real Academia de Bellas Artes de San Fernando. 25 marzo/3 mayo 1992. Madrid, Comunidad de Madrid - Real Academia de Bellas Artes de San Fernando, 1992. Aporta un estudio de Delfín Rodríguez Ruiz titulado «Imágenes de lo posible: los proyectos de Arquitectura premiados por la Real Academia de Bellas Artes de San Fernando (1753-1831)". 


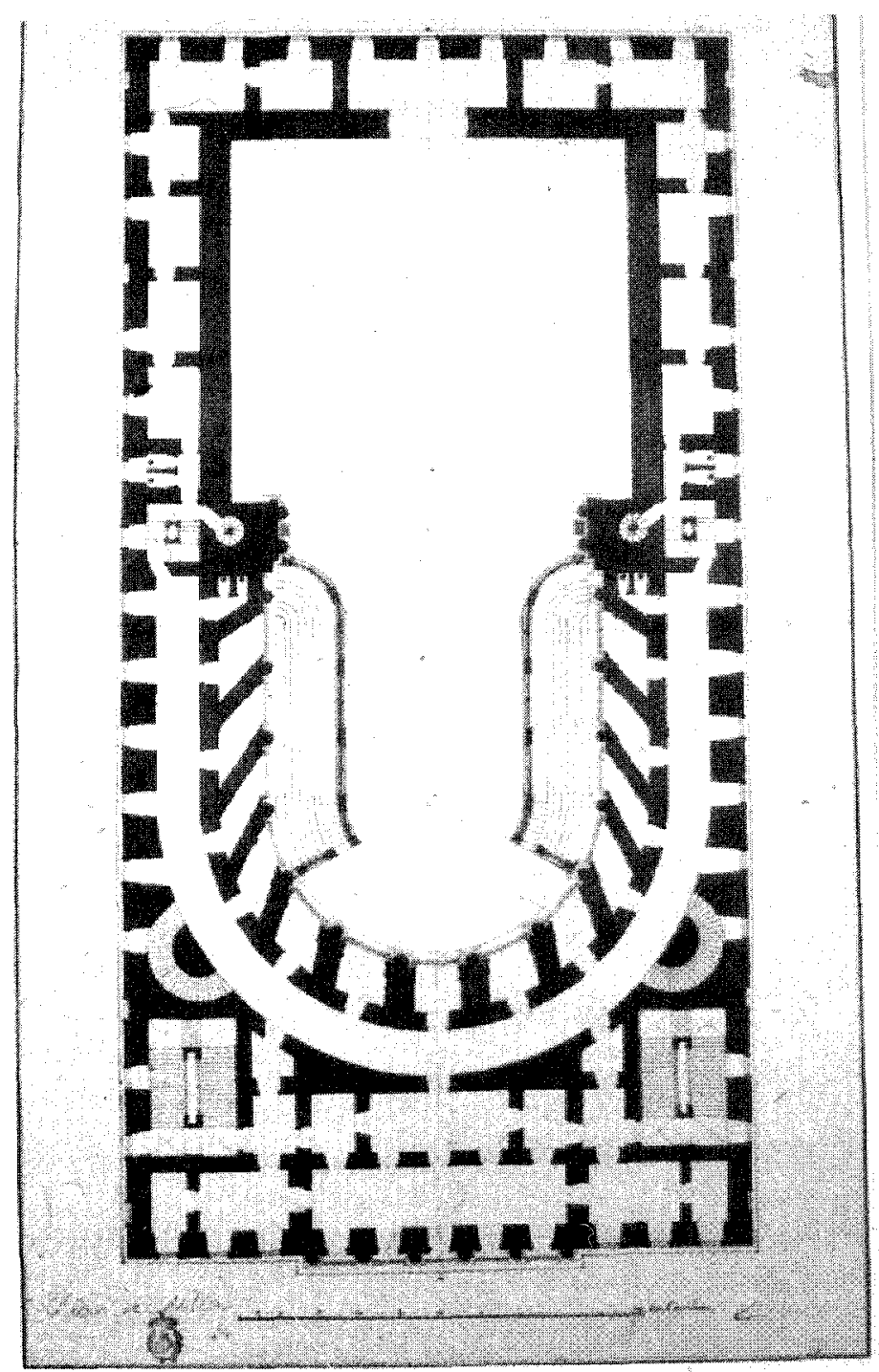

Lam. VII: Planta principal del proyecto para teatro de comedias españolas de Juan Milla 1772. Planta de campana interior inscrita en una $U$. 
en forma de $U$ de Milla, aunque no se despojase de las citas rococós. Tampoco se discutió en este período la curva del auditorio elíptica-oval de Patte, planta que conlleva, al parecer, un sentido formal en algo bastante más barroco por su mismo dinamismo. El método fue disculpado en función de su buena acogida por su carácter óptimo según las mismas leyes de la óptica y de la acústica, tal y como Patte lo había justificado.

No es extraño que la planta elíptica tuviera buena acogida en la España de finales de la llustración, pues había cierto precedente. Ventura Rodríguez, según Llaguno indicó, ya había diseñado en fecha tan temprana como es 1768 de orden del Consejo de Castilla un teatro de comedias para la ciudad de Murcia, en donde empleó la «figura semielíptica» en el interior, que tal autor no dudó en calificar de «condecoración de bello gusto» ${ }^{31}$. Y esto ocurría un año antes de que se inaugurara el teatro real de París diseñado por Moreau de planta elíptica truncada. ¿Ventura Rodríguez conoció a tal caso los términos del debate francés sobre la curva del auditorio entablado en esa misma década de los años sesenta?

Las mismas opciones en el auditorio estaban presentes en los dibujos teatrales para premios de arquitectura de la Academia valenciana de San Carlos, filial de la madrileña de San Fernando. Pero hay una evolución tanto en esa forma desde la $\mathrm{U}$ en herradura de Minguez de 1775 hacia lo elíptico del diseño de Vicente Ferrer de 1795 como en el empleo de un mayor número de habitáculos complementarios del teatro según se acerca el final del siglo. No falta la alternativa en forma de campana de Salvador Escrig, o quizás elipse acampanada, tal vez como una pervivencia rococó, que se centra en un conjunto bastante complejo con dos patios laterales y fachadas en avances y retrocesos.

Los diversos modelos teatrales del pasado -llegados de la Historia y de ese hoy que fue un momento denso de revisión y de recreación-, como clasicismo y cual alternativas también de una normativa clásica, estaban ya propuestos en estas formas de curvatura del auditorio para los espectadores. Al final de la llustración se había planteado en España una serie de modelos posibles, ecos del ayer lejano o del menos distante en el tiempo y del más próximo, reflejados y recreados en el presente con todas sus nuevas necesidades. Las premisas del debate, que se desarrolló en Italia y en Francia de las décadas de los sesenta, sobre todo, setenta y de los ochenta, estaban propuestas en España en los últimos diez años del siglo de la llustración a través de todos estos modelos de tan diversos

31 Llaguno, op. cit., t. IV, pág. 263. 
tipos, aunque siempre de un modo bastante provinciano: libros sobre teatro con sus tres modalidades de tratados clásicos, traducciones de obras de la época y estudios eruditos sobre teatros romanos españoles, construcciones hechas y proyectos irrealizados. España, de alguna forma y dentro de sus propias posibilidades en aquella época, manifestaba deseos, aunque como siempre tímidos, de incorporarse al debate. No obstante, el momento fundamental se desarrollaría en nuestro país treinta años después, en el segundo cuarto del XIX.

Sin embargo, al finalizar el siglo XVIII aún no habían terminado en Europa los debates sobre cuál de todos los modelos de curvas del auditorio era en realidad el mejor sistema para ser empleado en base a las leyes de la óptica y de la acústica. Su origen se halla en Italia, aunque Francia se incorporó a él al mediar el siglo de la llustración como una auténtica locomotora, hallando ciertos ecos en Inglaterra a través de Saunders.

Así, Carini Motta en 1676 en su "Tratado sopra la struttura de' teatri e scene» habia establecido las bases del historicismo y hasta del eclecticismo, iniciándolo ya en el último cuarto del siglo XVII, al comparar los teatros italianos y franceses desde finales del XVI. Pero su idea sería seguida por Scipione Maffei en 1753 en su «De teatri Antichi e Moderni». Por su parte Eneas Arnaldi había ofrecido en 1762 un proyecto de edificio para espectáculos inspirado en la Antigüedad, pero adaptado a su época, que recogió Milizia, en la «ldea di un Teatri... simile a' Teatri antichi». En ese mismo año el Conde Algarotti en el "Saggio sopra l'Opera in musica» defendió también el sistema clásico de auditorio semicircular, porque esta figura encerraba más espacio y debido a que los espectadores situados en su contorno veían el escenario en su totalidad al estar todos igualmente distantes del centro. No obstante, por motivo de la gran abertura del escenario prefirió el auditorio semielíptico longitudinal truncado. Este historicismo fue también propiciado por el propio Milizia al analizar los diferentes teatros existentes y aceptar el sistema de Arnaldi de adaptar al teatro clásico a la modernidad, estableciendo, así, un cierto eclecticismo historicista. Por último, Francesco Riccati en «Della construzione de' teatri secondo il costume d'ltalia, vale a dire, divisi in piccole logge" ya en 1790, estableció las bases de un hipotético nacionalismo teatral decimonónico al revalorizar el teatro en herradura y el empleo de los palcos, identificando este sistema con el teatro nacional italiano.

Este historicismo también lo habían promovido los arquitectos franceses en su debate de las décadas de los años sesenta, setenta y ochenta del siglo de la llustración con Dumont (1764), Cochin (1765), Chaumont (1766 y 1767), M. M., el manuscrito de Damun, Blondel, Roubo, y Noverre, 
quienes finalmente con Patte, parecían hallar en la curva elíptica del auditorio su propio sistema nacional, aún optando también internacionalmente por el semicírculo clasicista, que contraponer en razón de la acústica a la planta de herradura italiana, establecida más por motivos ópticos. Si Dumont prefirió el círculo clásico del auditorio, Cochin propuso el teatro elíptico transversal al modo del teatro Olímpico de Vicenza y Chaumont el elíptico longitudinal. Por su parte Blondel en su "Cours d'Architecture", indicó que una sala debía ser de forma circular o elíptica, siempre preferibles a la oblonga. Damun se mostró partidario del semicírculo clásico con gradas cubiertas por un pórtico columnado, semicírculo aceptado igualmente por Roubo en su "Traité de la construction des Théâtres \& des machines théâtrales». M.M. propuso cualquier curva de forma indiferente; es decir, desde la circular y semicircular, a la elíptica ya longitudinal ya transversal y hasta la de herradura. En su "Exposition des principes que l'on doit suivre dans l'ordonnance des Théâtres modernes" tan sólo proscribió las salas alargadas sobre dos línes rectas casi paralelas.

Quizás, Francia había polemizado siempre sobre el tipo de curva en función de la audición más que de la visión. Los italianos concedieron a los materiales constructivos un sentido básico en los problemas de la acústica, restándosela tal vez a la forma del auditorio. Los franceses en torno a la Revolución de 1789 también parecían preferir la galería abierta y democratizadora al sistema de los palcos, encerrados en sí mismos, tan italiano, justificada, no obstante, por Milizia y Patte por motivos sociales y económicos, pues con su construcción se subvencionaban los teatros. La democracia post-revolucionaria de Francia contrastaba, así, con él sentido aristocrático de Italia, que hallaba en el palco una serie de funciones múltiples como hábitat de diversión de muy diversa especie, del cual no quería o no podía prescindir.

La Academia madrileña - deudora institucionalmente de Francia, pero sobre todo de Roma desde el punto de vista estético, ciudad abierta y de encuentros en busca del clasicismo- quiso hacerse eco de tal polémica aún con algún retraso, pues las ideas, como los libros, en los que muchas veces se encierran para transportarse y difundirse, tardaban, por lo general, en llegar a nuestro país. Quizás por este motivo se introdujo entre los temas, que los maestros arquitectos debían disertar para conseguir el grado de incorporación de académico de mérito, el de cuál de los tipos de plantas semicircular o elíptica era mejor para construir un teatro según las leyes de la óptica y de la acústica. Eran las alternativas de Milizia y de Patte, síntesis de las metódicas y progresivas discusiones teóricas italianas y francesas. Ecos ya lejanos, pero aún no desaparecidos del todo, de un debate dieciochesco, racionalista y de base histórica, ya casi testimonial, 
que el nuevo historicismo propiciaba otra vez. No obstante, el romanticismo histórico, aún heredándolo, quitaría cierta importancia al promover una liberalización de esta planta según los gustos personales del arquitecto y del mecenas, y hasta de acuerdo con la misma configuración del terreno, en el cual este edificio se debía construir. Pero ahora en los albores del $x i x$ se seguía de alguna forma siendo deudores de tal polémica al buscarse un modelo de teatro nacional ${ }^{32}$.

No obstante, el debate tenía múltiples implicaciones de diversos diagnósticos. No se trataba tan sólo de hallar la mejor curva del auditorio para adecuarse a las leyes de la óptica y de la acústica. Había, además, otros muchos problemas, arquitectónicos, urbanísticos y hasta pictóricos y escultóricos, que resolver como la ubicación del teatro en una plaza de la ciudad y en función de su centro o de su periferia ${ }^{33}$. Sin embargo, no se podía olvidar el uso de los materiales más adecuados en esa lucha secular del arquitecto contra el fuego, que había dado al teatro una media de vida de cuarenta o cincuenta años, y el eco. Ambos aspectos le debían producir gran malestar y quizás desesperación: la piedra protegía al edificio de arder; pero el sonido reverberaba. Por el contrario, la madera era acústicamente ideal; mas atraía los incendios. También obsesionaba a este profesional el estamentalmente aristocrático palco, que Italia había hecho elemento arquitectónico propio de su teatro nacional, ante las necesiciades post-revolucionarias de hacer acceder a las masas burguesas. La compartimentación espacial del palco discrepaba de los espacios abiertos clásicos y democráticos de los graderíos.

32 Sobre el importante debate decimonónico sobre el teatro en la España del romanticismo hizo Juana María Balsalobre Garcia su memoria de licenciatura en la U.N.E.D., que dirigí, leída en octubre de 1993 con el título «La imágen académica del teatro español decimonónico: el teatro español y su censura en la Real Academia de Bellas Artes de San Fernando". Estudio que en la actualidad prosigue para presentarlo como tesis doctoral.

33 Una síntesis de la arquitectura del teatro español en: “Arquitectura teatral en España". Exposición de la Dirección General de Arquitectura y Vivienda. Barcelona, Secretaría General Técnica del MOPU, 1984. Incluye dos estudios de IgNASI SOLA MORALES titulados Arquitectura teatral y Los edificios en la ciudad. También: El lugar del espectáculo de ANTONI RAMÓN GraELLS; Las máquinas teatrales: arquitectura y escenografía de PEDRo NAvascués PALAcio, y Espacios de la vida social: los «otros» espacios de la arquitectura teatral por ANGEL LUIS FERINÁNDEZ MUÑOZ. Alude sobre todo al teatro español decimonónico. 